\title{
Cuidando de Pessoas Vivendo com HIV/Aids na Atenção Primária à Saúde: nova agenda de enfrentamento de vulnerabilidades?
}

\author{
Caring for People Living with HIV/Aids in Primary Health Care: a \\ new agenda for facing vulnerabilities?
}

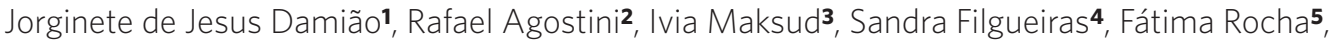
Ana Carolina Maia', Eduardo Alves Melo, $\mathbf{5}$

DOI: 10.1590/0103-1104202213211

1 Universidade do Estado do Rio de Janeiro (Uerj) Rio de Janeiro (RJ), Brasil. jjdamiao@yahoo.com.br

2 Universidade Cidade de São Paulo (Unicid) - São Paulo (SP), Brasil.

3 Fundação Oswaldo Cruz (Fiocruz), Instituto Nacional de Saúde da Mulher, da Criança e do Adolescente Fernandes Figueira - Rio de Janeiro (RJ), Brasil.

4 Secretaria Estadual de Saúde do Rio de Janeiro (SES-RJ) - Rio de Janeiro (RJ), Brasil.

${ }^{5}$ Fundação Oswaldo Cruz (Fiocruz), Escola Nacional de Saúde Pública Sergio Arouca (Ensp) - Rio Janeiro (RJ), Brasil.

6 Universidade Federal Fluminense (UFF), Instituto de Saúde Coletiva (ISC) Niterói (RJ), Brasil.
RESUMO A ampliação do papel da Atenção Primária à Saúde (APS) no tratamento de Pessoas Vivendo com HIV/Aids (PVHA) tem potencial de expandir o acesso ao cuidado de saúde. Este artigo visa analisar implicações da descentralização da assistência de PVHA para a APS na (re)produção ou redução de vulnerabilidades. Os conceitos de violência simbólica; interseccionalidade; precariedade e vulnerabilidades orientaram a entrada em campo e a análise dos resultados. Foram realizados grupos focais com profissionais, observação participante e entrevistas semiestruturadas com usuários e profissionais de duas unidades de APS na região central do município do Rio de Janeiro. Como principais resultados, destacam-se as implicações das vulnerabilidades associadas à violência armada e às questões de gênero no cuidado em saúde das PVHA, a existência de efeitos paradoxais da lógica territorial, bem como tensões entre a organização do processo de trabalho na APS e as necessidades/expectativas de usuários. Concluímos que a ampliação do acesso coexiste com a produção de novos riscos, que refletem na continuidade e qualidade do cuidado. Sublinhamos a necessidade de fortalecimento das interações trabalhador-usuário e da reflexão sobre novos arranjos para a organização dos processos de trabalho, que resultem em mais proteção e cuidado às pessoas, evitando a ampliação de vulnerabilidades.

PALAVRAS-CHAVE HIV. Atenção Primária à Saúde. Vulnerabilidades. Síndrome de Imunodeficiência Adquirida. Assistência integral à saúde.

\begin{abstract}
The expansion of the role of Primary Health Care (PHC) in the treatment of people living with HIV/Aids (PLWHA) has the potential to expand access to health care. This article aims to analyze the implications of the decentralization of services for PLWHA to PHC and its impact on the (re)production or reduction of vulnerabilities. The concepts of symbolic violence; intersectionality; precariousness and vulnerabilities guided the entry into the field and the analysis of the results. This study involved participant observation, focus groups with professionals and semi-structured interviews with users and professionals from two PHC units of the city of Rio de Janeiro. The results highlight the implications of vulnerabilities associated with armed violence and gender issues in health care, the presence of paradoxical effects of territorial logic, as well as tensions between the organization of work processes in PHC and the needs and expectations. Advances in the expansion of access coexist with the production of new risks that impact the continuity and quality of care. We underscore the need to strengthen worker-user interactions and to reconsider new arrangements for the organization of work processes that may result in more protection and care than in the expansion of vulnerabilities.
\end{abstract}

KEYWORDS HIV. Primary Health Care. Health vulnerability. Comprehensive health care. 


\section{Introdução}

Os avanços tecnológicos conquistados no enfrentamento da epidemia de HIV/Aids permitem o aumento da expectativa e qualidade de vida das Pessoas Vivendo com HIV/ Aids (PVHA) e têm potencial para acabar com a epidemia $\mathbf{1}$. No entanto, mesmo após quatro décadas de surgimento da Aids, ainda persistem condições socioculturais que criam vulnerabilidades para a infecção e para morbimortalidade pelo HIV/Aids. Condições estas que representam barreiras significativas para o controle da epidemia e para a adoção equânime das tecnologias biomédicas existentes em benefício das pessoas, comprometendo assim a qualidade do cuidado ofertado na rede de saúde ${ }^{2,3}$.

O conceito de vulnerabilidade tem origem no campo de direitos humanos e se expandiu para o campo da saúde, iluminando a construção de respostas para o enfrentamento da epidemia da Aids4,5. Sua compreensão tem buscado formular 'totalidades compreensivas', superando a dicotomização entre o individual e o coletivo na abordagem das dimensões implicadas na exposição ao vírus e no viver com HIV ${ }^{\mathbf{4} 6}$ : individual, social e programática.

Conforme destacam Ayres, Paiva, Buchalla ${ }^{6}$, a dimensão individual envolve a identidade pessoal, construída nas interações com o mundo, enquanto a dimensão social se relaciona aos contextos de organização política, econômica e sociocultural, e é perpassada por marcadores sociais da diferença, como gênero, raça, classe e geração. Por sua vez, a dimensão programática abrange políticas, serviços e ações institucionais, em conformidade com (e fruto de) processos e contextos político-sociais diversos.

Essa perspectiva é capaz de relacionar processos de saúde-doença-cuidado, a partir do entendimento de que políticas e serviços precisam ser pensados não somente como ferramentas para atender demandas de saúde estanques e apartadas do contexto em que são produzidas ${ }^{7}$.

A relação entre vulnerabilidades e Aids tem mão dupla. A pobreza e outros marcadores de exclusão social têm um papel na construção da vulnerabilidade à doença. Por outro lado, diferentes aspectos ligados ao viver com HIV/Aids reforçam e produzem novas vulnerabilidades decorrentes do estigma da doença, que persiste impactando a saúde das pessoas mesmo após quatro décadas da epidemia.

Tradicionalmente, o cuidado às PVHA se dava em ambulatórios de infectologia e o diagnóstico era realizado em Centros de Testagem e Aconselhamento. Buscando ampliar o acesso às ações de prevenção e diagnóstico do HIV, e, mais recentemente, ao tratamento das PVHA, a descentralização destas ações para unidades de Atenção Primária à Saúde (APS) vem ocorrendo paulatinamente em diversos municípios brasileiros ${ }^{\mathbf{8}, 9}$. $\mathrm{O}$ argumento passa pela reconfiguração da epidemia, pelo aumento do acesso à prevenção e tratamento e ampliação da capilaridade da APS, com a expansão da Estratégia Saúde da Família (ESF) a partir dos anos $2000^{10}$. No município do Rio de Janeiro, o crescimento da ESF ocorreu tardiamente e de forma acelerada, iniciando o acompanhamento das PVHA na APS em 2013"1.

A descentralização do cuidado em HIV/ Aids na APS tem levantado questões sobre um possível efeito paradoxal desta política. Ao mesmo tempo que, pela inserção da unidade de saúde na comunidade onde vivem seus usuários, potencializa o acesso a um cuidado singularizado, também pode, pela mesma razão, produzir vulnerabilidades que dificultam o acesso ao diagnóstico e a adesão ao tratamento antirretroviral, em função do estigma da doença, que ainda permanece ${ }^{12}$. Nesse sentido, o objetivo do presente artigo é analisar implicações da descentralização da assistência à saúde de PVHA para a APS na (re) produção ou redução de vulnerabilidades, com ênfase para aquelas relacionadas à violência armada e às relações de gênero. 


\section{Percurso metodológico}

Os dados apresentados neste artigo derivam da pesquisa 'O Cuidado às Pessoas com HIV/ Aids na Rede de Atenção à Saúde’. Os achados aqui debatidos referem-se ao campo realizado em duas unidades de APS, ambas localizadas na região central do município do Rio de Janeiro, com ampla oferta de serviços públicos de saúde, desde o nível de atenção básica até uma rede de serviços especializados. Os sujeitos incluídos na pesquisa foram usuários, profissionais de saúde e representantes de movimentos sociais de HIV/Aids.

A pesquisa se beneficiou de referenciais teórico-metodológicos do campo das ciências sociais e humanas e da saúde coletiva para orientar a entrada em campo e a análise dos resultados. Os dados foram interpretados em diálogo com os conceitos de violência simbólica ${ }^{13}$ (violência despercebida, modo de dominação sutil), interseccionalidade ${ }^{\mathbf{1 4}}$ (instrumentalidade teórico-metodológica à inseparabilidade estrutural do racismo, capitalismo e cis-heteropatriarcado, percebendo as múltiplas camadas de estruturas de opressão, sobretudo de gênero, raça e classe), vulnerabilidade ${ }^{6}$ (interação das dimensões individual, social e programática constituintes das vulnerabilidades da pessoa à doença) e precariedade ${ }^{15}$ (reconhecimento de que determinados enquadramentos epistemológicos permitem que certas vidas sejam tratadas como mais precárias que outras e, portanto, menos passíveis de luto e de proteção). Foram realizados dois grupos focais com Agentes Comunitários de Saúde (ACS) em cada uma das unidades, e entrevistas semiestruturadas com usuários (16), profissionais da saúde (64 entre ACS, médicos e enfermeiros) e ativistas do movimento social de Aids (7), além de observação participante em salas de espera, atividades de grupos e em outras ações realizadas pelos serviços selecionados. As entrevistas e grupos focais foram gravados e transcritos para posterior codificação temática.
A pesquisa foi aprovada pelo Comitê de Ética em Pesquisa (CEP) da Fundação Oswaldo Cruz (Fiocruz) e pelo CEP da Secretaria Municipal de Saúde do Rio de Janeiro, através dos pareceres de número 2309404 e 2559884 , respectivamente. Para garantir a confidencialidade dos participantes, os nomes reais foram substituídos por fictícios.

\section{O cenário do estudo e perfil dos usuários}

Embora localizadas na região central e no 'asfalto', as duas unidades estudadas encontram-se nas margens de favelas, em territórios permeados pela pobreza e com ostensiva presença de violência decorrente da guerra contra o tráfico de drogas. A área de abrangência de uma delas inclui pontos de prostituição, dois conjuntos habitacionais e uma região com grande concentração de cortiços. Já o território da segunda unidade engloba uma área tradicional de classe média da cidade.

Ambas as unidades se localizam em uma área programática - como são chamadas as regionais de saúde no município do Rio de Janeiro - bastante heterogênea e estratégica para a circulação na cidade, pois nela estão situados o centro comercial e administrativo do município, além da rodoviária e de um dos aeroportos.

O perfil das PVHA acessadas pela pesquisa apresentou múltiplos contornos: homens e mulheres em relacionamentos estáveis ou não, hétero e homoafetivos, jovens e adultos, pessoas em situação de prostituição, pessoas vivendo em situação de rua, pessoas ligadas ao tráfico de drogas, beneficiários de programas sociais. A maioria das pessoas era pobre, com baixa escolaridade e negras, evidenciando a interação das vulnerabilidades geradas pelo contexto político e sociocultural e as vulnerabilidades individuais expressas no comportamento dos indivíduos ${ }^{6}$, mas havia ainda pessoas consideradas de classe média, atendidas também na rede privada de saúde. 


\section{Resultados e discussão}

Considerando que a epidemia de HIV/Aids é, antes de tudo, uma epidemia de significa$\operatorname{dos}^{16}$, ela se manifesta e se retroalimenta a partir dos entrecruzamentos de diferentes vulnerabilidades, atravessando as práticas de cuidado no cotidiano dos serviços de saúde e sedimentando limites e possibilidades de cuidado individual e coletivo.

Nas unidades de APS e em entrevistas com gestores e ativistas do movimento social ligado à Aids, os achados evidenciaram diferentes questões capazes de comprometer ou melhorar as práticas de cuidado. As desigualdades de acesso ao diagnóstico e tratamento das PVHA tiveram presença marcante da violência urbana e das relações de gênero, em um contexto de entrecruzamento de vulnerabilidades, fortemente marcado pelo estigma. Por este motivo, privilegiamos estes temas para organizar os dados do estudo.

\section{Barreiras de acesso ao diagnóstico e tratamento impostas pela violência no território}

A violência no território é percebida pelos profissionais de saúde no cotidiano do trabalho e também nas relações estabelecidas com os usuários. Ela afeta sobremaneira tanto os processos de adoecimentos como as estratégias possíveis de assistência e vem se constituindo um desafio para o setor saúde, por suas repercussões na vida das pessoas e comunidades. No caso brasileiro, a violência se manifesta com uma íntima relação com a pobreza e outras vulnerabilidades ${ }^{\mathbf{1 7}}$.

A violência armada foi apontada, sobretudo pelos ACS, como um desafio capaz de limitar o acesso ao diagnóstico e tratamento das PVHA, suscitando medo de expulsão do seu local de moradia. Soma-se à violência armada inúmeros relatos de violência simbólica, presentes no cotidiano dos ACS e dos demais moradores do território. Entre as histórias narradas pelos ACS, não é incomum os casos de pessoas que descobrem o diagnóstico e saem da comunidade com medo de serem mortas pelo tráfico. "Vou embora. Se eu ficar aqui, eles vão me matar" (GF ACS 1 AP 1).

Este temor faz com que alguns usuários prefiram não publicizar seu diagnóstico na comunidade onde residem, com receio de serem alvo de algum tipo de represália.

[...] Uma questão clara é da Diana. Ela é da área, o filho dela é do tráfico e assim, quando ela soube foi aquele choque. Ela não queria que ninguém soubesse, porque ela não queria que a notícia se espalhe e chegue lá em cima no ouvido do pessoal. Eu consegui segurar o sigilo dela... só descobriram porque um dia ela veio buscar a receita, ela estava com pressa e ela pediu pra deixar a receita grampeada no acolhimento, eu deixei, mas o ACS foi lá e olhou... E aí meio que uma contou pra outra, aí eu virei e falei, isso não sai daqui de dentro. (Cadu Roque. Médico UBS 1).

O depoimento de um ativista que vive com HIV, Hildemar, revela a violência simbólica sofrida diante da exposição de seu diagnóstico de HIV. Ele morava em um bairro na zona oeste da cidade. Embora o episódio não tenha ocorrido no território das duas unidades onde nosso estudo realizou o campo, revela como é grave a exposição do diagnóstico em função de uma prática pouco cuidadosa da equipe de saúde local.

Primeiro eles foram a mim e perguntaram se eu era soropositivo, e eu neguei. Eles falaram que iriam na Clínica da Família do local e que se soubessem, eles iriam voltar, e fazer o que eu já sabia que acontecia com pessoas aidéticas lá dentro, no condomínio. Aí demorou uns dois dias, para mim eles tinham esquecido, aí a clínica me ligou bem cedo dois dias depois falando que eles tinham acabado de sair de lá, para eu sair com a roupa do corpo e com os documentos, que eles iriam atrás de mim. Aí eu saí. Como já tinha um fato de que eles tinham matado um menino que era soro lá, então eu saí e não voltei mais. (Hildemar, Movimento social). 
Esse processo de violência no território é fortemente marcado pelo estigma e discriminação, comprometendo a efetividade do cuidado e acarretando, entre outras consequências, vulnerabilidades constituídas por ações/atitudes do próprio serviço de saúde e suas equipes (vulnerabilidade programática) 4,18.

Numa história narrada por Luís, médico, ativista do movimento da luta contra a Aids, o despreparo de um ACS levou à situação de expulsão do território.

O Agente Comunitário de Saúde chegou de bicicleta com um papel na mão e disse: 'Você tem consulta de Aids dia tal e dia tal'. [...] Ele estava construindo sua casa, tudo lá dentro, e ele teve que sair da comunidade. Foi expulso. (Luis, Movimento social).

Estes relatos evidenciam vulnerabilidades programáticas e nos remetem à reflexão de Bonet ${ }^{18}$ sobre a necessidade de lidar com o paradoxo presente na APS, que ao mesmo tempo que representa um instrumento potente na diminuição das desigualdades de acesso à saúde, pode reforçá-las.

Além dos desafios impostos às ações propriamente de assistência às PVHA, a violência e o estigma da Aids impõem dificuldades também para a realização de ações de testagem e outras atividades de prevenção, pois sua realização parece dar indícios de que há casos de HIV no território, o que provoca questionamentos dos trabalhadores do tráfico como "Veio falar disso, tem alguém por aqui [...] tem alguma coisa. O que houve?".

Esta situação exige flexibilidade das equipes de saúde em ajustar seus planejamentos, fluxos, protocolos e, até mesmo, ter atenção com determinados gestuais, de modo que as ações de testagem e prevenção possam ser realizadas, como apontam as ACS:

Tem que ter todo um planejamento já de não olhar para ninguém, de não falar resultado pra ninguém.
Caso esses cuidados não sejam tomados, [...] isso ameaça diretamente a integridade física dos sujeitos.

Como alerta uma ACS, "se ele [um traficante] se embatucar com alguém, pronto. Aí, vai dar ruim pra alguém" (GF ACS 2 AP 1).

Esses achados evidenciam barreiras às ações de cuidado, impondo a organização de processos de trabalho que levem em conta esses atravessamentos, de modo que o cuidado integral possa se efetivar. A impossibilidade das equipes em realizar estas adaptações, conforme a necessidade das pessoas e seus territórios de vida, acrescenta outras vulnerabilidades programáticas, ampliando as barreiras de acesso.

Os jovens inseridos no tráfico vivem à margem da sociedade, à medida que buscam preservar suas identidades e têm uma circulação restrita a áreas em que se sentem mais protegidos, evitando confrontos com a polícia. Ao mesmo tempo, a exigência de documentos para realização de exames ou dispensação de medicamentos torna-se um entrave, capaz de reforçar a vulnerabilidade deste grupo.

ACS: Tudo tem que ter documento (Teste rápido). ACS: E se ele não fornecer fica difícil de colocar esse paciente no sistema. (GF ACS UBS 2).

Os conflitos no território atravessam o cotidiano do trabalho dos profissionais da APS, demandando constantes ajustes no gerenciamento das ações. No entanto, há dificuldades para flexibilização diante das normas.

A gente sabe que eles [jovens do tráfico] ali estão dentro da boca de fumo. E a gente queria muito fazer uma ação [...] entrar, falar com eles, colher o BAAR [Pesquisa de bacilos álcool-ácido resistentes, para o diagnóstico da tuberculose] deles, só que a gente sempre trava nessa questão dos documentos... porque eles não vão dar documento. (GF ACS UBS 2). 
A vulnerabilidade programática, neste caso, foi produzida à medida em que a norma virou uma 'camisa de força', impedindo a efetividade do cuidado. $\mathrm{O}$ agir profissional deveria responder ao princípio da universalidade, quando os usuários não têm documentação, alguns procedimentos alternativos poderiam ser acionados.

Durante nosso trabalho de campo, relatos marcantes sobre questões relacionadas aos jovens que trabalham para o tráfico de drogas tornaram visíveis sua exclusão e a violação de seu direito ao cuidado em saúde. Sobretudo pela necessidade de manterem o anonimato e uma imagem de poder na comunidade, que poderia ser abalada com doenças estigmatizadas como a Aids e outras Infecções Sexualmente Transmissíveis (IST).

Em visita domiciliar, um dos pesquisadores acompanhou um diálogo entre a ACS e uma PVHA que relatava a necessidade de ir à clínica, mas estava com receio, porque há poucos dias havia sido expedido o segundo mandado de prisão contra ela (Diário de Campo, Agostini, 2018).

Nas histórias narradas por pessoas que vivem em situação de rua, percebe-se como a violência simbólica ${ }^{13}$ de práticas assistenciais reforçam as vulnerabilidades que vivenciam. Simária, mulher negra, ficou presa por quatro anos no Complexo Penitenciário da Frei Caneca e 15 anos no 'semiaberto', por homicídio com 'arma branca'. Foram 38 facadas no ex-marido que a cegou de um dos olhos e deixou uma grande cicatriz em seu braço. Hoje ela é fugitiva do sistema carcerário e passou a viver em situação de rua (Diário de campo de Agostini, 2018). Simária contou sobre diversas passagens por unidades de saúde onde, na maior parte das vezes, era tratada com "nojo" por ser "moradora de rua". Nunca era submetida a exames, nem mesmo físicos. "Aplicavam uma injeção e mandavam embora". Essas experiências de violência levaram-na a crer que um dos serviços de emergência que frequentava foi responsável por "roubar" um de seus rins e infectá-la com o vírus do HIV (Entrevista com usuária da UBS 1).
A história da Simária nos faz refletir sobre como estas vidas são marcadas pela precariedade. Judith Butler ${ }^{19}$ afirma que há 'corpos abjetos', cujas vidas não são consideradas 'vidas' e cuja materialidade é entendida como 'não importante'. O racismo estrutural atravessa suas histórias, explica e justifica a aceitação da sociedade de que certas vidas podem ser perdidas, pois não importam, são descartáveis ${ }^{20,21}$.

A conexão de vulnerabilidades sociais e individuais se expressa na vivência de situações de risco para o HIV e podem comprometer tanto o acesso ao serviço de saúde quanto a adesão ao tratamento e medidas preventivas, como demonstra o relato de um ACS participante do grupo focal.

Ninguém vai querer falar que tem HIV, ainda mais 'ator' [forma pela qual os ACS se referem aos jovens que trabalham no tráfico], porque vive uma vida muito promíscua. Um ator tem várias mulheres [...] ele não vai querer ser esculachado. [...] o cara está no auge da popularidade dele com várias mulheres, várias novinhas. Não pode porque o cara está bichado. Nenhum deles usam camisinha. É muito difícil usar camisinha ali [entre as pessoas envolvidas no tráfico]. [...] Tá bichado é (ou está com Aids) [...] Ou está com alguma IST. (GF ACS UBS 2).

Apesar do acesso aos cuidados em saúde no âmbito do Sistema Único de Saúde (SUS) ser garantido também aos sujeitos que estão em pena privativa de liberdade, a experiência da pesquisa mostrou que esse processo nem sempre acontece tal como preconizam os dispositivos legais. No caso relatado por uma ACS, o paciente interrompeu o tratamento para o HIV quando foi preso e retornou à unidade para reiniciá-lo. "[...]ó, eu estou sem fazer o tratamento há dois anos porque eu estive preso. E ele fazia o tratamento lá na pneumologia" (GF ACS UBS 1).

Essa situação nos remete à inexistência de ações intersetoriais (saúde e justiça), revelando mais uma vulnerabilidade programática, neste 
caso, contribuindo para a quebra de continuidade do cuidado/tratamento do referido usuário.

Ainda que não se materialize efetivamente em superação das vulnerabilidades produzidas pela violência e das limitações que acarretam, a visibilidade desta questão tem contribuído para atitudes de implicação e responsabilização por parte dos profissionais de saúde, que, no caso dos ACS, é expressa também nos laços de solidariedade. "[...] a gente pede a mãe, a irmã, a mulher: Vai lá no posto então. Pega o remédio... a gente tenta ver o máximo" (ACS GF 2).

\section{Relações desiguais de gênero e suas implicações no cuidado à saúde}

As desigualdades de gênero contribuem para aumentar a vulnerabilidade das mulheres, tanto em relação à exposição das IST/HIV/ Aids quanto ao seu acompanhamento nos serviços de saúde.

Diferentes relatos sobre mulheres vivendo com HIV/Aids, que tiveram agravamento da doença culminando em mortes, chamam a atenção para o entrecruzamento de vulnerabilidades que afeta este grupo.

Eu tive duas amigas que vieram a falecer e no finalzinho de vida elas vinham pro posto, e uma na época, ela não falava para ninguém o que ela tinha, falava que era macumba, que tinham feito macumba, mas na realidade a família dela sabia que ela tinha. Realmente eu vim a saber no dia que ela pediu para eu ver a receita dela, mas assim, ela morreu pessimamente mal. Eram duas amigas novas. Uma com vinte e poucos e a outra com 32 no máximo. Chegaram na unidade em estado cadavérico. (GF ACS 1 AP 1).

Chama a atenção nesta narrativa o fato de que as mulheres eram conhecidas da ACS e, mesmo assim, a unidade de saúde não foi capaz de identificar estes casos no território. Apesar da proximidade, ao contrário do que se espera, outros fatores programáticos dificultaram o acesso. $O$ cuidado em relação ao HIV para a mulher está mais estruturado à condição materna, incluindo a realização de exames para o diagnóstico de HIV em gestantes e prevenção da transmissão vertical. Mas as vulnerabilidades sociais e a violência são características presentes na trajetória das mulheres que vivem com HIV $^{\mathbf{2 2}}$, ao que se soma a falta de informações sobre sexualidade e contracepção e o pouco acesso aos serviços de saúde para as mulheres negras ${ }^{23}$. Fatores estruturais, como desigualdades raciais, de gênero, opressão sexual e de idade, interagem de maneira sinérgica produzindo mais desvantagens e agregando vulnerabilidades a estes grupos². Nas histórias narradas, permeadas por manifestações de violência simbólica, é difícil não identificar entrecruzamentos dessas vulnerabilidades.

Pelos relatos dos profissionais de saúde, as mulheres foram percebidas como potencialmente expostas à infecção do HIV, em função da pouca autonomia na negociação do uso da camisinha com os seus parceiros e da violência. Em uma das histórias de gestantes com sífilis, a ACS relatou a dificuldade de tratamento porque o companheiro "força a ter relações com ele" sem camisinha.

O medo de que os companheiros descubram o diagnóstico induz algumas mulheres a deixarem de fazer o tratamento ou que o façam de forma irregular, por causa de estratégias para não serem descobertas, como o ocultamento de cartões de gestantes ou de medicamentos que possam revelar o diagnóstico. Analisando a literatura da área ${ }^{\mathbf{2 4}}$, também percebemos que dinâmicas envolvendo segredo e acobertamento fazem parte da vida dessas mulheres.

O sucesso no manejo do sigilo passa a ser um fator decisivo para a garantia do acesso e da continuidade do tratamento, uma vez que a unidade está inserida no território e, portanto, sua quebra pode ter impacto na vida familiar e social.

A Aids vista como uma doença associada à promiscuidade desloca o olhar da comunidade à mulher soropositiva como 'aventureira', 
visibilizando a existência de uma vida sexual fora da conjugalidade, o que se contrapõe aos ideais da 'mulher respeitável'24,25.

[...] qualquer tipo de doença eles associam só às mulheres. É aquele negócio, se eles estão com alguma coisa é aquele negócio: 'Quem me passou foi a fulana'. Eles nunca imaginam que ele mesmo já tenham o vírus ou qualquer coisa, e eles estejam passando. Geralmente sempre é: 'A vagabunda, a sem vergonha, a safada que me passou'. Aí rola um esculacho. (Bianca, paciente UBS 2 AP1).

Os ACS relataram casos em que as mulheres não revelaram o diagnóstico aos parceiros que, por sua vez, não fazem a testagem para o HIV. Percebemos em algumas histórias que a revelação do diagnóstico de HIV ou de sífilis pode significar risco de vida, sobretudo para mulheres que vivem com homens ligados ao tráfico, cujas relações frequentemente são descritas como violentas e discriminatórias ${ }^{26}$.

A gente já teve caso de doença sexualmente transmissivel, que era parceira de um cara do movimento e ela estava morrendo de medo dele descobrir porque... ela sabia que ela seria cobrada se ele descobrisse. Então, foi todo um trabalho de sigilo. [...] imagina se fosse [HIV]. (ACS5 AP1 GF).

[...] ele chegou a vir na unidade querendo acompanhar a consulta dela para saber. (GF ACS UBS 1).

Contudo, o acompanhamento dessas mulheres pelos profissionais de saúde pode ser uma estratégia de enfrentamento das vulnerabilidades ao HIV/Aids, no contexto das desigualdades de gênero.

Resposta eu acho que não tem. Esse paciente que era aqui de Nova Iguaçu, ele é exatamente esse caso. Falaram que o cara ia matar ela, e eu acredito [...]. E eu problematizava com ela. E eu acho que o fato de eu ter acolhido, de entender, de ouvir, disponibilizar um tempo com ela [...] as coisas ficaram amenizadas, ele veio, teve o diagnóstico, foi tranquilo, não matou ela, acho que até fortaleceu a questão entre os dois, começou a tratar. (Nando, médico, Grupo focal).

A interseccionalidade entre cor/raça e gênero pode ser notada nas histórias nar$\operatorname{radas}^{\mathbf{1 4}}$, embora as vulnerabilidades específicas experimentadas pelas mulheres negras passassem como despercebidas nos relatos dos profissionais. A referência à cor da pele só apareceu como forma de identificar alguma personagem, utilizando-se sinônimos para designar a cor preta da pele, como que para 'amenizar' a referência à cor. “É uma escurinha, né?”. Isto é confirmado na observação dos pesquisadores, que identificam que as pacientes eram, na maioria, negras, principalmente as protagonistas das histórias que remontavam às situações de vida mais precárias. Paradoxalmente, os ACS são eles mesmos pertencentes às camadas populares, que, no Brasil, constituem-se por uma maioria de pessoas negras, mas 'a negação' explicitada pelo não reconhecimento da sua realidade relaciona-se com o processo de alienação forçada pela experiência cotidiana do racismo ${ }^{27}$.

O não reconhecimento de características que representam desvantagens para determinados grupos implica em oportunidades perdidas pelo serviço de saúde, de desenvolver ações capazes de minimizar o impacto destas vulnerabilidades.

A história de uma das pacientes negras entrevistadas envolve uma vida de pobreza, adoecimento e violência familiar. Laurinda foi trazida do Maranhão para viver com um 'catador de lixo' que precisava de uma pessoa que lavasse a sua roupa e fizesse sua comida. No início, disse que queria usar camisinha, mas ele não quis e, como era "boba", acabou aceitando. No entanto, meses depois descobriu que ele vivia com hepatite e, logo depois, soube do diagnóstico do HIV/ Aids. A relação dos dois era atravessada pela violência de gênero e pelo racismo, revelados, entre outras situações, pela forma de tratamento comumente dispensada a ela 
pelo companheiro: "preta imunda". Esse tratamento evidencia uma das expressões do racismo na representação do corpo negro como um corpo abjeto, imundo e excluído socialmente ${ }^{28}$. As mulheres negras são afetadas por uma dupla carga de opressão, evidenciando a intersecção de diversos marcadores sociais. Não é possível separar raça e gênero, uma vez que construções racistas se alicerçam em papéis de gênero e as relações de gênero conferem maior impacto na experiência do racismo ${ }^{27}$.

Avanços conquistados com políticas sociais nas décadas recentes não foram suficientes para diminuir as desigualdades raciais no País. A equidade entre brancos e negros passa pelo enfrentamento da questão racial. O conceito de racismo institucional nos ajuda a compreender os processos de reprodução da hierarquia racial, principalmente no âmbito das políticas públicas ${ }^{29}$. Esta compreensão no âmbito do SUS implica no reconhecimento do fracasso em promover ações adequadas às necessidades das pessoas em função do impacto do racismo sobre sua saúde, como na história da Simária narrada acima, recolocando o desafio da equidade de acesso e do acesso ao cuidado no âmbito do SUS.

Uma das histórias narradas pelos ACS envolvia um jovem trabalhador do sexo, que se recusou a fazer o tratamento e acabou indo a óbito depois de um esforço da equipe para adesão ao tratamento. Ele vivia com HIV, tuberculose, hepatite e sífilis. "O combo completo” segundo uma das ACS.

A médica pediu pra fazer uma busca ativa dele da TB [tuberculose], porque o teste estava positivo. E eu fui lá, mas ele não veio buscar o resultado. E, aí, quando eu cheguei, ele estava na cama com outro rapaz. Aí, se enrolou numa toalha e veio me atender. Aí, ele falou pra mim: 'Não, ninguém pode saber, hein' [...] Você sabe que eu trabalho na rua e eu estou com HIV, eu tenho sífilis e ninguém pode saber aqui. (GF ACS UBS 1).
O segredo da situação envolvia a necessidade de sobrevivência. A família não sabia e a equipe só tomou conhecimento depois de um teste rápido solicitado pelo enfermeiro, embora ele tenha confidenciado ao ACS que já sabia que estava doente.

Depois do óbito, os protocolos de vigilância em saúde levaram a instalar um processo de busca ativa.

Se instaura, no entanto, um dilema ético já que o fato de solicitar a realização de exames após o falecimento do usuário é o mesmo que assinar um atestado do conhecimento da sua condição por parte da equipe de saúde. [...] os profissionais resolveram agir. [...] Era um quarto, sem janela, que tinha uma cama de casal e todo mundo dormia junto. E quando, a primeira coisa (que ouvi), quando eu fui lá, 'Ele estava com tuberculose, né? Pode falar que ele estava pegado'. (GF ACS UBS 1).

Embora os Homens que fazem Sexo com Homens (HSH) e mulheres transexuais ainda continuem sendo alguns dos grupos mais acometidos pelo HIV/Aids, as histórias envolvendo vulnerabilidades relacionadas à identidade de gênero nestes grupos não tiveram destaque nos achados. Na observação participante, foram personagens menos presentes nos espaços e tampouco foram relatados nas entrevistas com profissionais e ACS. Esses 'não dados' nos fazem questionar se este grupo está sendo acolhido pela APS e se suas vulnerabilidades são percebidas.

Os achados da pesquisa ratificam o poder das relações desiguais de gênero como um importante fator de vulnerabilização das mulheres ao HIV/Aids e apontam para a invisibilidade destas questões para alguns grupos, como os HSH e mulheres transexuais. Chamamos atenção sobre o papel dos profissionais de saúde da APS no enfrentamento destas vulnerabilidades. Este tema tem sido contemplado nas consultas com os usuários? Tem sido debatido em diferentes espaços de atendimento coletivo? Tem sido problematizado nas reuniões de equipe e 
contribuído para refletir sobre a abordagem e condução de determinados casos?

A qualificação do cuidado, envolvendo abordagens sensíveis aos grupos vulneráveis, demanda reflexão crítica por parte das equipes de saúde sobre suas práticas profissionais e uma reorganização dos processos de trabalho, assim como o reconhecimento e respeito às diferenças e às questões identitárias ${ }^{\mathbf{3 0}}$.

\section{Considerações finais}

Os achados deste estudo permitiram visualizar a interação dos três eixos de vulnerabilidade (individual, social e programática). Dar visibilidade a estas vulnerabilidades é o primeiro passo para a superação das desigualdades que aumentam as chances de aquisição do HIV e criam barreiras para o seu enfrentamento.

O estigma e a discriminação ligados ao HIV/Aids ampliam a precariedade de vida das pessoas, comprometendo, por exemplo, o acesso e a qualidade do cuidado recebido no SUS.

Mesmo diante das vulnerabilidades produzidas pelo cuidado às PVHA, neste contexto de violência armada e de relações desiguais de gênero, atravessadas pela violência simbólica e outras vulnerabilidades, como as de raça, o espaço da APS também representa um elemento potencial para o seu enfrentamento, à medida que reconhece as necessidades das pessoas, pode entender melhor os motivos da baixa adesão ao tratamento, pode construir estratégias diferenciadas para lidar com as limitações e, com isso, facilitar a criação de vínculo.

No entanto, este potencial em promover equidade encontra limites nas práticas cotidianas, que reforçam processos de discriminação ou desconsideram as diferenças. A APS pode representar uma ameaça ou aprofundar os processos de vulnerabilização diante do temor da quebra de sigilo, acrescendo vulnerabilidades programáticas à violência armada do território e ao sexismo, fortemente presente na vida dessas pessoas.

Identificamos avanços, potências e novos riscos (sobretudo relacionados ao sigilo), com expressões no acesso, na continuidade e qualidade do cuidado. Sublinhamos a necessidade de fortalecer as interações trabalhador-usuário, a qualificação do acesso e a reorganização dos processos de trabalho em direção à equidade, para que a política de descentralização resulte mais em proteção e efetividade do cuidado do que na ampliação de vulnerabilidades. A visibilidade das vulnerabilidades programáticas e a reflexão sobre elas, por parte dos trabalhadores da saúde, é fundamental para a garantia do direito à saúde e a defesa da vida.

A noção de vulnerabilidade avança em relação à de risco na medida em que considera a sua produção social como relações de vulnerabilização, e não um estado essencial ou natural. O olhar para a vulnerabilidade, no entanto, não deve desconsiderar, a priori, a possibilidade de existência de linhas de força que operam como resistência (à sujeição/opressão), ou como afirmação de potência de vida. O cuidado a PVHA na APS tem como efeito (e não apenas como intenção ou retórica) a ampliação de vulnerabilidades ou, ao contrário, o seu reconhecimento e tentativa de redução ou ainda a aposta na potência de vida das PVHA, a partir de um reconhecimento ético-político de que todas as vidas valem a pena.

Por fim, identificamos a necessidade de novas pesquisas que possam fornecer outros elementos para respondermos à questão sobre se o modelo da atenção primária favorece o cuidado singularizado de PVHA.

\section{Agradecimentos}

Agradecemos a leitura e revisão gramatical de Gustavo Antonio Mendelsohn de Carvalho. 


\section{Colaboradores}

Damião JJ (0000-0001-6591-3474)*, Filgueiras SL (0000-0003-2971-734X)* e Rocha F (00000002-5500-7061)* contribuíram para concepção e delineamento do estudo, coleta e análise dos dados, redação e revisão final do manuscrito. Maksud I (0000-0002-3465-151X)* e Melo

\section{Referências}

1. Joint United Nations Programme on HIV/Aids. 9090-90: An ambitious treatment target to help end the Aids epidemic. Geneva: UNAIDS; 2014.

2. Parker R. Interseções entre estigma, preconceito e discriminação na saúde pública mundial. In: Monteiro S, Villela W, organizadores. Estigma e Saúde. Rio de Janeiro: Fiocruz; 2018. p. 61-80.

3. Parker R. O fim da Aids? Genebra: Associação Brasileira Interdisciplinas de Aids; 2011.

4. Ayres JRCM, Calazans GJ, Saletti Filho HC, et al. O risco, vulnerabilidade e práticas de prevenção e promoção da saúde. In: Campos GWS, Minayo MCS, Akerman M, et al., organizadores. Tratado de Saúde Coletiva. São Paulo; Rio de Janeiro: Hucitec; Fiocruz; 2006. p. 375-417.

5. Mann J. Saúde pública e direitos humanos. Physis Rev Saúde Coletiva. 1996; 6(1,2):135-45.

6. Paiva V, Ayres JR, Buchalla CM. Direitos humanos e vulnerabilidade na prevenção e promoção da saúde: uma introdução. In: Paiva V, Ayres JR, Buchalla CM, organizadores. Vulnerabilidade e direitos humanos-
EA (0000-0001-5881-4849)* contribuíram para concepção e delineamento do estudo, coleta e análise dos dados e revisão crítica do manuscrito. Agostini R (0000-0001-80719362)* e Maia AC (0000-0002-4144-0526)* contribuíram para concepção e delineamento do estudo, coleta e análise dos dados e redação do manuscrito.
Prevenção e promoção da saúde - Da doença à cidadania. Livro I. Curitiba: Juruá; 2012. p. 9-23.

7. Calazans GJ, Pinheiro TF, Ayres JRCM. Vulnerabilidade programática e cuidado público: Panorama das políticas de prevenção do HIV e da Aids voltadas para gays e outros HSH no Brasil. Sex Salud y Soc. 2018; 29:263-93

8. Brasil. Ministério da Saúde. 5 passos para a implementação do Manejo da Infecção pelo HIV na Atenção Básica - Guia para gestores. Brasília, DF: MS; 2014.

9. Brasil. Ministério da Saúde. Caderno de Boas Práticas em HIV/Aids na Atenção Básica. Brasília, DF; 2014.

10. Malta DC, Santos MAS, Stopa SR, et al. A Cobertura da Estratégia de Saúde da Família (ESF) no Brasil, segundo a Pesquisa Nacional de Saúde, 2013. Ciênc. Saúde Colet. 2016; 21(2):327-38.

11. Melo EA, Maksud I, Agostini R. Cuidado, HIV/Aids e atenção primária no Brasil: desafio para a atenção no Sistema Único de Saúde? Opinião e análise. Rev Panam Salud Pública. 2018; (42):151.
*Orcid (Open Researcher and Contributor ID). 
12. Zambenedetti G, Silva RAN. O paradoxo do território e os processos de estigmatização no acesso ao diagnóstico de HIV na atenção básica em saúde. Estud Psicol. 2015; 20(4):229-40.

13. Bourdieu P. Compreender. In: Bourdieu P, organizador. A miséria do mundo. 9. ed. Petrópolis: Vozes; 2012. p. 683-732.

14. Akotirene C. Interseccionalidade. São Paulo. São Paulo: Jandaíra; 2020.

15. Butler J. Quadros de Guerra. Quando a vida é passível de luto? Rio de Janeiro: Civilização Brasileira; 2015.

16. Treichler P. Homophobia, and Biomedical Discourse: An Epidemic of Signification. In: Routledge, organizador. London: Cultural Studies; 1987. p. 263-305.

17. Dahlberg LL, Krug EG. Violência: um problema global de saúde pública. Ciênc. Saúde Colet. 2007; (11):116378.

18. Bonet O. Discriminação, Violência Simbólica e a Estratégia Saúde da família: reflexões a partir do texto de Richard Parker. In: Monteiro S, Villela W, organizadores. Estigma e saúde. Rio de Janeiro: Fiocruz; 2018. p. 25-45.

19. Butler J. Bodies That Matter: On the Discursive Limits of "Sex.” New York: Routledge; 1993.

20. Mbembe A. Necropolítica. São Paulo: N-1 Edições; 2018.

21. Mbembe A. Crítica da razão negra. São Paulo: N-1 Edições; 2018.

22. Barbosa RM, Pinho AA, Santos NS, et al. Exploring the relationship between induced abortion and HIV infection in Brazil. Reprod Health Matters. 2012; 20(supl39):80-9.
23. Villela WV, Barbosa RM. Trajectories of women living with HIV/Aids in Brazil. Progress and permanence of the response to the epidemic. Ciênc. Saúde Colet. 2017; 22(1):87-96.

24. Silva LMF. Fazendo a diferença: as dinâmicas de conjugalidade sorodiscordante para o HIV/Aids. João Pessoa: Universidade Federal da Paraíba; 2012.

25. Daniela R. Subjetividade feminina e soropositividade. In: Barbosa RM, Parker R, organizadores. Sexualidades pelo avesso: direitos, identidades e poder. São Paulo; Rio de Janeiro: Editora 34; IMS/UERJ; 1999. p. 121-36.

26. Cortina MOC. Mulheres e tráfico de drogas: Aprisionamento e criminologia feminista. Rev Estud Fem. 2015; 23(3):761-78

27. Kilomba G. Memórias da plantação: Episódios de racismo cotidiano. Rio de Janeiro: Cobogó; 2019.

28. Fernandes VB, Souza MCCC. Identidade Negra entre exclusão e liberdade. Rev do Inst Estud Bras. 2016; (63):103-20.

29. Theodoro M, Jaccoud L, Osório RG, et al. As políticas públicas e a desigualdade racial no Brasil: 120 anos após a abolição. Brasília, DF: Ipea; 2008.

30. Siqueira SAV, Hollanda E, Motta JIJ, et al. Políticas de promoção de equidade em saúde para grupos vulneráveis: O papel do Ministério da Saúde. Ciênc. Saúde Colet. 2017; 22(5):1397-406.

Recebido em 12/04/2021

Aprovado em 29/11/2021

Conflito de interesses: inexistente

Suporte financeiro: não houve 